\title{
Stature of early Europeans
}

\author{
Michael Hermanussen
}

Privat Dozent Dr. med., Aschauhof, 24340 Altenhof, Germany

\begin{abstract}
The ancestors of modern Europeans arrived in Europe at least 40,000 years before present. Preglacial maximum Upper Palaeolithic males (before 16,000 BC) were tall and slim (mean height 179 $\mathrm{cm}$, estimated average body weight $67 \mathrm{~kg}$ ), while the females were comparably small and robust (mean height $158 \mathrm{~cm}$, estimated average body weight $54 \mathrm{~kg}$ ). Late Upper Palaeolithic males (8000$6600 \mathrm{BC}$ ) were of medium stature and robusticity (mean height $166 \mathrm{~cm}$, estimated average body weight $62 \mathrm{~kg}$ ). Stature further decreased to below $165 \mathrm{~cm}$ with estimated average body weight of 64 $\mathrm{kg}$ in Neolithic males of the Linear Band Pottery Culture, and to $150 \mathrm{~cm}$ with estimated average body weight of $49 \mathrm{~kg}$ in Neolithic females. The body stature of European males remained within the range of 165 to $170 \mathrm{~cm}$ up to the end of the $19^{\text {th }}$ century.
\end{abstract}

Key words: Stature, Palaeolithic, Mesolithic, Neolithic, Eastern Mediterranean

The ancestors of modern Europeans arrived in Europe at least 40,000 years before present. Of very tall stature, they experienced extremely cold conditions, especially during the maximum of glacial expansion around 16,000 BC. Nevertheless, they succeeded well and relatively quickly replaced the Neanderthals.

Some 10,000 years ago, the end of the last glacial expansion (the Pleistocene-Holocene transition) provoked, within a very short period of time, a dramatic change of climate in Europe. The cold wet climate of the late glacial period changed into the Pre-Boreal cool-moist climate (8000-6600 BC), and further improved in central Europe at the beginning of the Mesolithic (warm-moist Boreal climate 6600-5400 BC).

Address correspondence and requests for reprints to: Michael Hermanussen, Aschauhof, 24340 Altenhof, Germany, e-mail: hermanussen.aschauhof@t-online.de

Received 01-04-03, Revised 16-05-03, Accepted 20-06-03
The climatic optimum was reached during the Atlantic Period (5400-3000 BC) with temperatures that were even warmer than today. The climatic changes caused major ecological developments. The cold semi-arid steppe of the Pleistocene-Holocene transition was covered with birch and pine forests, and after 6000 $\mathrm{BC}$, with hazel. Mixed forests appeared during the Atlantic Period, followed by oak and beech forests during the Bronze and Iron Age. With the rising of the temperatures, the cold-adapted large mammals, such as the reindeer, migrated farther to the North and to the East, and were replaced by smaller species which are still endemic in these areas now. Palaeolithic and Mesolithic people were hunter-gatherers but, due to the climatic changes, were forced to either follow the large animals they were accustomed to consume, or adapt culturally to the new and warmer environment. Those who stayed developed agriculture, changed their diets, and started to use cereals as the major source of starchy food. Constant gathering of 
large amounts of wood for domestic activities and fuel contributed to substantial deforestation. And when people intensified agriculture in the third millenium $\mathrm{BC}$, employing deep plowing and using draft animals, they not only grew many species of cereal plants, lentils and peas, but also reared sheep, goats, cattle and pigs. A variety of food sources was used including game, birds and fish, as well as wild plants which served as food supplementation when the growing season was over $^{1}$.

Parallel to the climatic changes, morphological changes occurred in the European populations, first between the Upper Palaeolithic and Mesolithic (first transition around $6600 \mathrm{BC}$ in Central and Northeast Europe, and some 2,000 years earlier in the Eastern Mediterranean), and again between the Mesolithic and Neolithic (second transition around $2800 \mathrm{BC}$ in Central and Northeast Europe, but around 7000 BC in the Eastern Mediterranean). It is not clear whether the morphological changes were due to gene flow or to local evolution, but most studies indicate that the transition between final Palaeolithic and Mesolithic populations was due to local conditions ${ }^{2}$.

Pre-glacial maximum Upper Palaeolithic males (before 16,000 BC) were tall and slim (mean height $179 \mathrm{~cm}$, estimated average body weight $67 \mathrm{~kg}$ ), but the females were comparably small and robust (mean height $158 \mathrm{~cm}$, estimated average body weight $54 \mathrm{~kg}$ ). The "Venus of Vestonice", a Palaeolithic idol of some 24,000 years of age (Figure 1), might be considered a delightful representative of the short and stout females of this age. Late Upper Palaeolithic males (8000-6600 $\mathrm{BC}$ ) were of medium stature and robusticity (mean height $166 \mathrm{~cm}$, estimated average body weight $62 \mathrm{~kg}$ ). Stature further decreased below $165 \mathrm{~cm}$ (estimated average body weight $64 \mathrm{~kg}$ ) in Neolithic males of the Linear Band Pottery Culture, and to $150 \mathrm{~cm}$ (estimated average body weight $49 \mathrm{~kg}$ ) in the Neolithic females $^{3}$. The Western European samples were particularly affected by the decrease in stature. The Eastern Europeans remained quite tall with stature around $173 \mathrm{~cm}$ for males and $160 \mathrm{~cm}$ for females throughout the Mesolithic ${ }^{4}$. Similar measurements were supplied by Angel for Eastern Mediterranean people (Table 1) though it should be kept in mind that the latter populations underwent the cultural changes considerably earlier than the Central and Eastern Europeans ${ }^{5}$.

Piontek and Vancata meta-analysed morphologi-

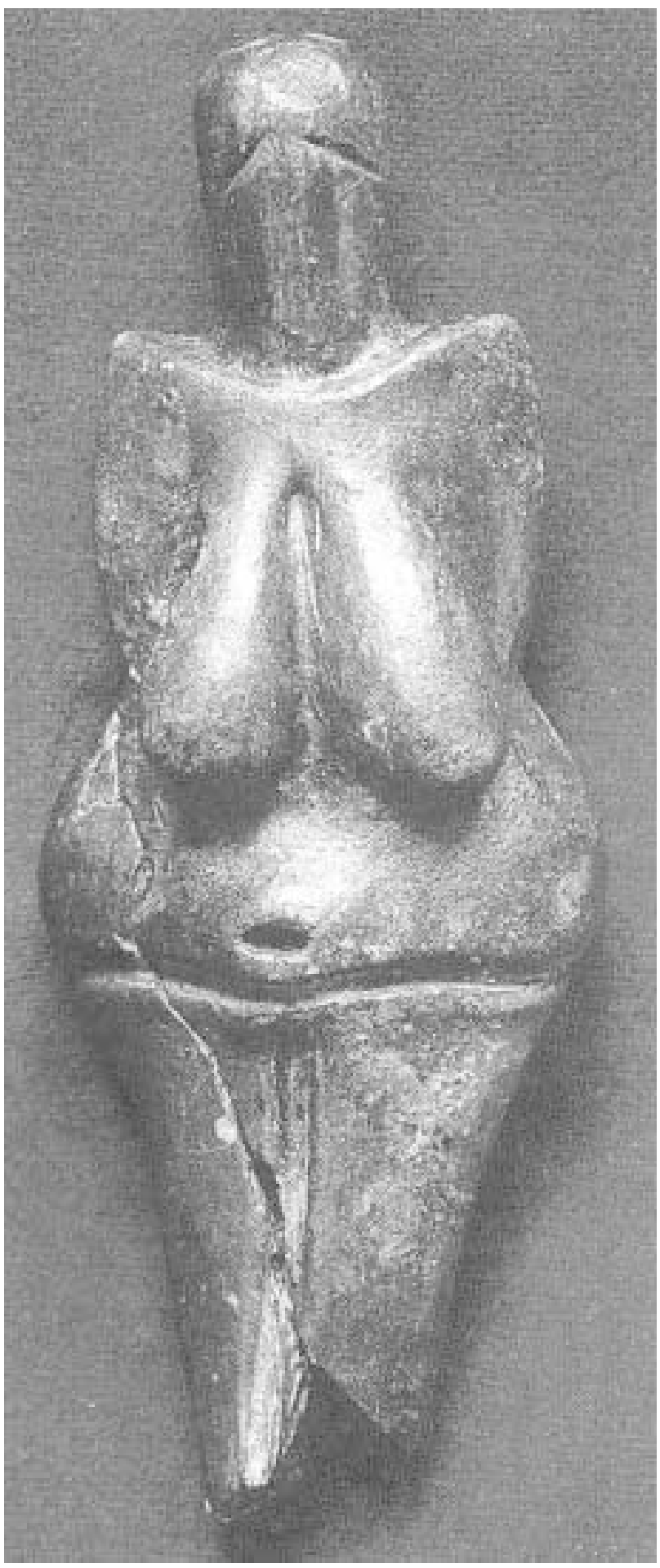

Figure 1. The "Venus of Vestonice", a Paleolithic idol dated to c. 24,000 years ago, discovered near Dolni Vestonice, Southern Moravia, Czech Republic.

cal changes in both body size and body shape during the European transition to agriculture and described 
Table 1. Changes of stature and population density in the Eastern Mediterranean region (Angel 1984)

\begin{tabular}{|c|c|c|c|}
\hline \multirow[t]{2}{*}{ Period } & \multicolumn{2}{|c|}{ Body height } & \multirow{2}{*}{$\begin{array}{c}\text { Estim. population density } \\
\left(\text { persons } / \mathbf{k m}^{2}\right)\end{array}$} \\
\hline & Males & Females & \\
\hline Palaeolithic (earlier than $9000 \mathrm{BC}$ ) & 177.1 & 166.5 & 0.1 \\
\hline Mesolithic (9000-7000 BC) & 172.5 & 158.7 & 0.15 \\
\hline Early Neolithic (7000-5000 BC) & 169.6 & 155.5 & 1.5 \\
\hline Late Neolithic (5000-3000 BC) & 161.3 & 154.3 & 7 \\
\hline Early Bronze (3000-2000 BC) & 166.3 & 152.9 & 10 \\
\hline Middle People (2000-1500 BC) & 166.1 & 153.5 & 18 \\
\hline Bronze Kings (1450 BC) & 172.5 & 160.1 & \\
\hline Late Bronze (1450-1150 BC) & 166.8 & 154.5 & 30 \\
\hline Early Iron (1150-650 BC) & 166.7 & 155.1 & 20 \\
\hline Classic $(650-300 \mathrm{BC})$ & 170.5 & 156.2 & 36 \\
\hline Hellenistic (300 BC-120 AD) & 171.9 & 156.4 & 33 \\
\hline Imperial Roman & 169.2 & 158 & 25 \\
\hline
\end{tabular}

marked sexual dimorphism in the Early Upper Palaeolithic population ${ }^{3}$. The females had relatively long tibia, a long femoral neck and a larger femoral head than the males. The sexual dimorphism decreased in the more recent populations. Upper Palaeolithic humans not only were taller and had more robust bones in comparison with the Linear Band Pottery Culture Neolithic people; they also had longer limbs, a shorter trunk and, similar to modern African people, very long forearms and crural segments. The low brachial index* is a very recently acquired characteristic of White Europeans.

The transition to agriculture also influenced the tempo of maturation. Data indicate that girls in hunter-gatherer populations reached menarche on average 3 years later (at the end of 16) than girls in traditional agricultural populations (at the age of 13). Also the starting age of reproduction in hunter-gatherers was on average as late as 19 years, whereas in traditional agriculturists, it occurred at 18 years.

The reasons for the shortening of body stature during the warming of the European climate are essentially unknown. Various hypotheses have been discussed of which dietary considerations are favoured. The Palaeolithic diet was rich in protein and fibres with no refined carbohydrates, and is considered well

\footnotetext{
* brachial index 100 times the length of the arm from the head of the radius to the styloid process divided by the length of the arm from the acromion to the head of the radius
}

adapted for humans ${ }^{6}$. Palaeolithic population density was small, there was enough food for everybody, and there is no evidence of major endemic disease. Adult longevity, at 35 years for males and 30 years for females, implies fair to good general health during the Upper Palaeolithic. Females always died earlier because of the extra stress of pregnancy and dangers of childbirth, combined with shifting camp, carrying burdens, and presumably doing much of the food collecting and cooking ${ }^{5}$.

The quality of the diet did not change much during the whole span of the Upper Palaeolithic, but its quantity may have decreased after the last glacial expansion $^{2}$. The use of stable isotopes, $13 \mathrm{C}$ and $15 \mathrm{~N}$, which allows the study of animal protein and edible plant intake, is a technique developed to explore the diet of past populations. When applied to the Palaeolithic-Neolithic transition, the isotopes broadly show a diet rich in protein at the end of the glacial period, a diversification, with emphasis on fish resources during the Mesolithic, and an impoverishment during the Neolithic.

During the Mesolithic population density did not significantly increase, but there is evidence of increased migration, with multiple documents of violent deaths and new endemic diseases (malaria, hookworm). However, in the Neolithic the population rapidly expanded while the signs of violence declined after the advent of agriculture. Neolithic populations were 10 to 50 times as dense as in the Palaeolithic. 
Angel estimated a Neolithic population density of 2-5 persons $/ \mathrm{km}^{2}$ for the Eastern Mediterranean ${ }^{5}$. New cereal crops supported this expansion, and the amount of meat eaten decreased to about $10-20 \%$ of the Upper Palaeolithic optimum.

Body stature of historic Europeans remained within the range of $165-170 \mathrm{~cm}$ for males, and $155-160 \mathrm{~cm}$ for females up to the end of the $19^{\text {th }}$ century. Stature closely mirrored the cultural and socio-economic circumstances, and has been used for analysing health, living standard and economic background ${ }^{7}$. Particularly complete documents of stature have been published in the Netherlands where average body height of young males increased from $165 \mathrm{~cm}$ in 1863 to 184 $\mathrm{cm}$ in $1997^{8,9}$. There is evidence that most modern European populations are now catching up in height towards an average of some $180-182 \mathrm{~cm}$ in males, and some $168-170 \mathrm{~cm}$ in females. It is interesting to note that, though modern humans have returned to the body stature of their Early Palaeolithic ancestors, they retain the modern proportions with short forearms and short crural segments.

\section{REFERENCE}

1. Haduch E 2002 The human biology of the Neolithic and Bronze age population of Poland In: Bennike P, Bodzsar E, Susanne C (eds) Ecological aspects of past human set- tlements in Europe. Eötvös University Press, Budapest; pp, 143-156.

2. Froment A 2002 Biological evolution of populations during the early Holocene transitions In: Bennike P, Bodzsar E, Susanne C (eds) Ecological aspects of past human settlements in Europe. Eötvös University Press, Budapest; pp, 41-60.

3. Piontek J, Vancata V 2002 Transition to agriculture in Europe: evolutionary trends in body size and body shape In: Bennike P, Bodzsar E, Susanne C (eds) Ecological aspects of past human settlements in Europe. Eötvös University Press, Budapest; pp, 61-92.

4. Formicola V, Giannecchini M, 1999 Evolutionary trends of stature in upper Paleolithic and Mesolithic Europe. J Hum Evol 36: 319-333.

5. Angel JL 1984 Health as a crucial factor in the changes from hunting to developed farming in the Eastern Mediterranean In: Cohen MN, Armelagos GJ (eds) Paleopathology at the origins of agriculture. Academic Press, New York; pp, 51-73.

6. Cordain I, Eaton SB, Brand Miller J, Mann N, Hill K, 2002 The paradoxical nature of hunter-gatherer diets: meat-based, yet non-atherogenic, Eur J Clin Nutr 56(Suppl 1): 542-552.

7. Komlos J, Cuff T 1998 Classics in anthropometric history. Scriptura Mercaturae Verlag, St. Katharinen, Germany.

8. Van Wieringen JC 1986 Secular growth changes In: Falkner F, Tanner JM (eds) Human growth, Plenum Press, New York, London; pp, 307-331.

9. Fredriks AM, Buuren Sv, Burgmeijer RJF, et al, 2000 Continuing positive secular growth change in the Netherlands 1955-1997. Ped Res 47: 316-323. 